\title{
Do NTSB Statistics Support Current FAA Third Class Medical Policy?
}

\author{
Don Morris \\ Southern Illinois University, Carbondale
}

\begin{abstract}
Third Class Medical Reform is currently being considered by the FAA and by Congress. This study analyzes past incident data gathered by the NTSB from 1982 to the present to determine if a link exists between the amount of time that has elapsed since a pilot's medical certification and his or her likelihood of involvement in an incident or accident caused by medical incapacitation or impairment. A control population of 26,987 incidents was formed from all recorded incidents in which the pilot held a valid third class medical. This population was used to compare with a smaller population of 172 incidents for which the NTSB has determined that medical incapacitation or impairment not related to illegal drug or alcohol use was at least a factor. A Chi-Squared distribution returned a 17\% probability that the two populations were identical. Incidentally, descriptive statistics of the control population show an unexpected negative linkage between recentness of medical certification and likelihood of being involved in an incident $\left(\mathrm{R}^{2}=.821\right)$. This counterintuitive finding indicates that recent third class medical certification correlates to increased pilot risk, rather than increased levels of safety.
\end{abstract}

\section{Background}

If a pilot is involved in an incident or accident, they are required to notify the National Transportation Safety Board (NTSB) (49 CFR 830.15). The NTSB investigates the incident and, whenever possible, determines contributing factors. They record these along with details of the incident in the enhanced Accident Data Management System (eADMS) database. The database has hundreds of thousands of entries, and is publicly available. One of the details recorded for each occurrence in the database is the date of the pilot's last medical exam.

In order to maintain pilot safety, the Federal Aviation Administration (FAA) requires pilots to see a designated medical examiner (DME) to certify that they are medically fit to fly (14 CFR 61.23). The DME checks the pilot's physical condition, current medications, and medical history. If the DME finds that the pilot is capable of safely operating an aircraft and is unlikely to develop any conditions that would put them in danger while operating an aircraft, they are certified as medically fit. Unfortunately, as time elapses, a pilot's condition may unexpectedly deteriorate. This is why medical certificates only last a certain period of time before they must be renewed. Current FAA regulations require medical certificates to be renewed in intervals from six to 60 calendar months, depending on the class of medical certificate and the age of the pilot at the time of the exam (Federal Aviation Administration, 2008).

In order to exercise the privileges of an airline transport pilot, a pilot must have a first class medical. Commercial pilot privileges require a second class medical. Private pilot privileges require a third class medical. Currently, third class medical reform is before the FAA and Congress (Aircraft Owners and Pilots Association, 
2012; Pilots Bill of Rights 2, 2015). Those advocating reform say that the current system is excessively burdensome and expensive (Aircraft Owners and Pilots Association, 2012; Air Facts Journal, 2013). It is also, they add, redundant. Most pilots have already gone through some form of basic medical fitness check in order to receive a driver's license (Aircraft Owners and Pilots Association ..., 2012). They advocate that a State issued driver's license be allowed to replace the FAA specific third class medical certificate.

Proponents of medical reform say there is "almost zero link" between medical certification and safety (Aircraft Owners and Pilots Association, 2012; Goyer, 2014). Opponents of reform point out that past statistics cannot show the incidents and accidents that have been prevented by the system (Webb, 2014), and thus the statistics show that the system is working. However, actual statistical analysis is noticeably absent from the discussion. There seems to be a legitimate reason for this. The researcher's search for published statistical analyses of third class medical effectiveness produced no results. It seems that the actual numbers are not known. This could explain why FAA policy on third class medicals was shaped by a statistical analysis performed on air traffic controllers, and not on private pilots (Aircraft Owners and Pilots Association ..., 2012).

It is the researcher's hope that this study will be the beginning of an evidence based discussion on the effectiveness of the third class medical. This study cannot hope to determine whether or not medical reform is wise. It can, however, begin the discussion with a thorough investigation of the historic effectiveness of the third class medical as revealed by past NTSB data.

\section{Rationale}

It is logical to assume that any safety enhancement provided by medical certification will be greatest on the day of the medical exam. Over time, as unforeseen changes occur in the pilot's condition, its effect will wane. If the time that has elapsed since the last medical is plotted against the number of incidents, any relationship between these two variables should become apparent. In the absence of unknown codependent factors, a positive correlation between the two factors would indicate that the medical certification program is preventing incidents. If no correlation exists, this would seem to indicate that medical certification program is not preventing incidents. A negative correlation would indicate that a fresh medical certificate is associated with an increased risk of being involved in an incident - which is certainly not the goal of the program. Figure 1 shows the three most likely theoretical distributions based on illustrative data, with the "slight positive correlation" being the normally assumed shape of the graph. The expectation of this correlation is the presumptive basis for current FAA medical policy.

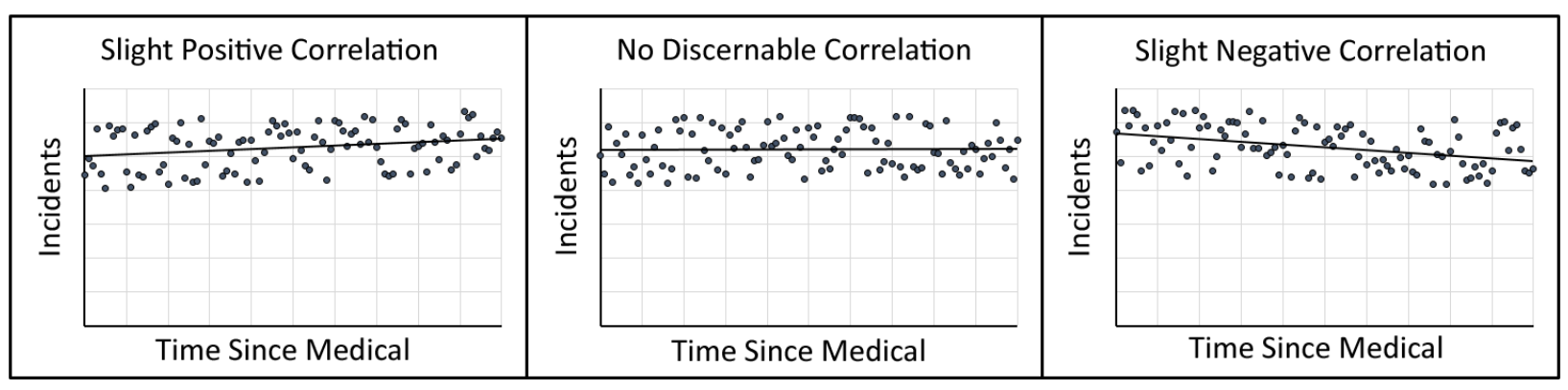

Figure 1. Possible theoretical distributions 


\section{Data}

This study defines two separate populations both taken from the eADMS database covering the time period from January $1^{\text {st }}$ of 1982 and extending to April 30 $30^{\text {th }}$ of 2015.

1. The first population will be referred to as the control population. It consists of all incidents in which a pilot had a valid third class medical, a valid date of last medical was recorded, and a valid pilot age was recorded. This population includes 26,987 distinct incidents.

2. The second population will be referred to as the research population. It consists of all the incidents out of the control population in which the NTSB determined that impairment or incapacitation (not relating to alcohol or illegal drug usage) was at least a factor. This population includes 172 distinct incidents.

The final data required to complete this study is the percentage of elapsed time between the issuance of the last medical and each incident that has been recorded in the database. Obtaining this data is not simple because the regulations pertaining to medical duration changed twice during the time period covered by the data (Federal Aviation Administration, 2008). Between 1982 and 1996, all third class medicals were valid for 24 calendar months. Between 1996 and 2008, third class medical validity for those under the age of 40 was extended to 36 calendar months. After 2008, third class medical validity for those under 40 years of age was again extended - this time to 60 calendar months. Conditional statements were used to model these regulations, and the percentage of time that had elapsed from the medical at the time of the incident was added to the data. This was done for both populations. Descriptive statistics for each population are shown in table 1.

Table 1.

Time is shown as the percentage of time elapsed from the valid medical time period

\begin{tabular}{|c|c|c|}
\hline \multicolumn{3}{|c|}{ Descriptive Statistics from Each Population } \\
\hline \hline & Control & Research \\
\hline Sample Size & 26987 & 172 \\
\hline Avg. Time Ellapsed & $43.6 \%$ & $47.2 \%$ \\
\hline Stand. Dev. & $28.6 \%$ & $26.7 \%$ \\
\hline
\end{tabular}

\section{Analysis}

Preliminary analysis was the same for both populations. Probability histograms (0 to 100) were constructed by rounding the percentage of time elapsed to the nearest percent, and by doubling the number of occurrences in the 0 and 100 buckets to compensate for the fact that these buckets were only half the width of the rest. Scatter plots were made for each population, and a regression line was calculated for each. These plots are shown in figures 2 and 3 , along with regression lines and their respective $\mathrm{R}^{2}$ values. For simplicity sake, only linear regressions were used in this study, although other unknown models might better fit the data. As can be seen from figure 2, the regression line for the control population has a strongly negative slope. This in counterintuitive, as it appears to associate recentness of medical exam with increasing risk of accident or incident, rather than with increasing levels of safety. Figure 3 shows the regression line for the research 
population. It has a similar negative slope, but both the slope and the coefficient of determination are less pronounced.

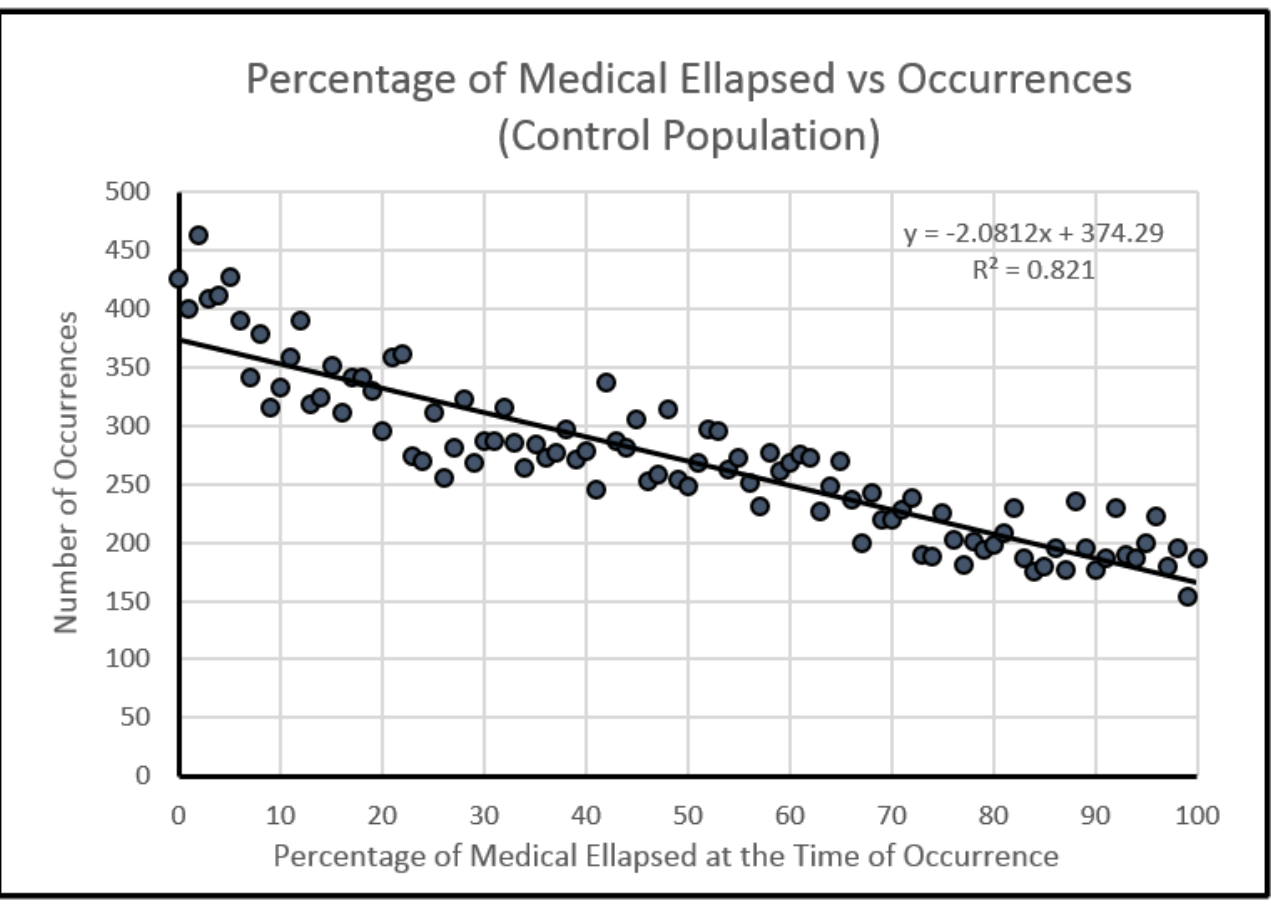

Figure 2. Percentage of medical elapsed vs. occurrences (Control population)

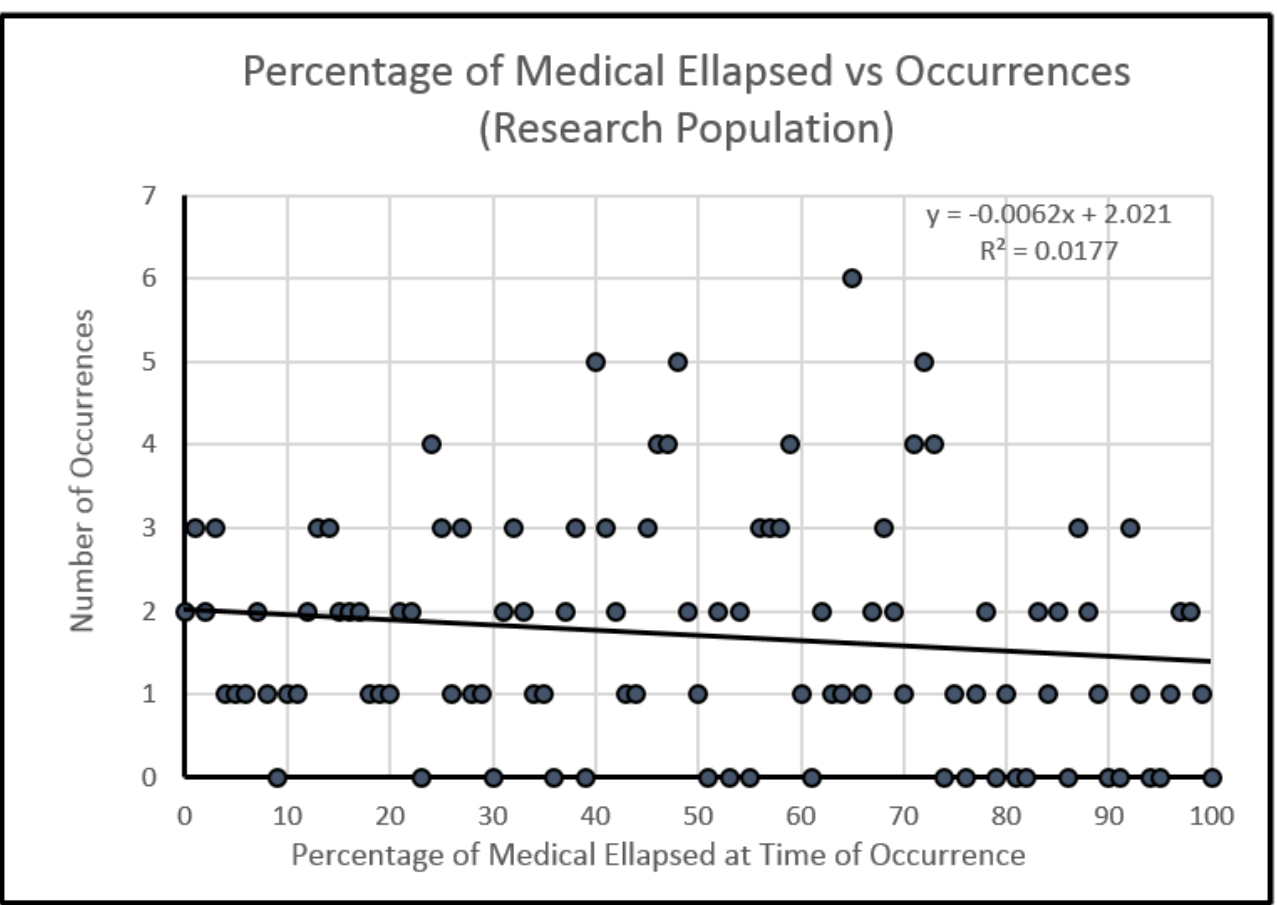

Figure 3. Percentage of medical elapsed vs. occurrences (Research population) 
The objective of this study is to determine if a link exists between time elapsed and the risk of being involved in an incident involving incapacitation or impairment. The control population shows a definite link, but this is the likelihood of being in an "incident," and not the likelihood of being involved in an "incident involving impairment or incapacitation." In order to show the latter, it is necessary that the research population be statistically distinguishable from the control population.

In accordance with conventional hypothesis testing logic, two alternative hypotheses can be identified. The research hypothesis is that the research population can be statistically distinguished from the control population. This is to say that an underlying variable other than random chance is statistically unlikely to have created the observed differences between them. The null hypothesis is that the research population cannot be statistically distinguished from the control population. This is to say that the observed differences are within the level that is likely explained by random factors.

In order to test the null hypothesis, the control population was used to calculate how many occurrences would be expected to occur in the research population for each histogram bucket, assuming that the populations were indistinguishable. This was determined by scaling the control population for sample size. The expected occurrences were then compared to the actual occurrences found in the research population using a Chi Squared test for goodness of fit. This test shows a probability of $17 \%(\mathrm{p}=0.17)$ that the differences between the two populations are due to random factors.

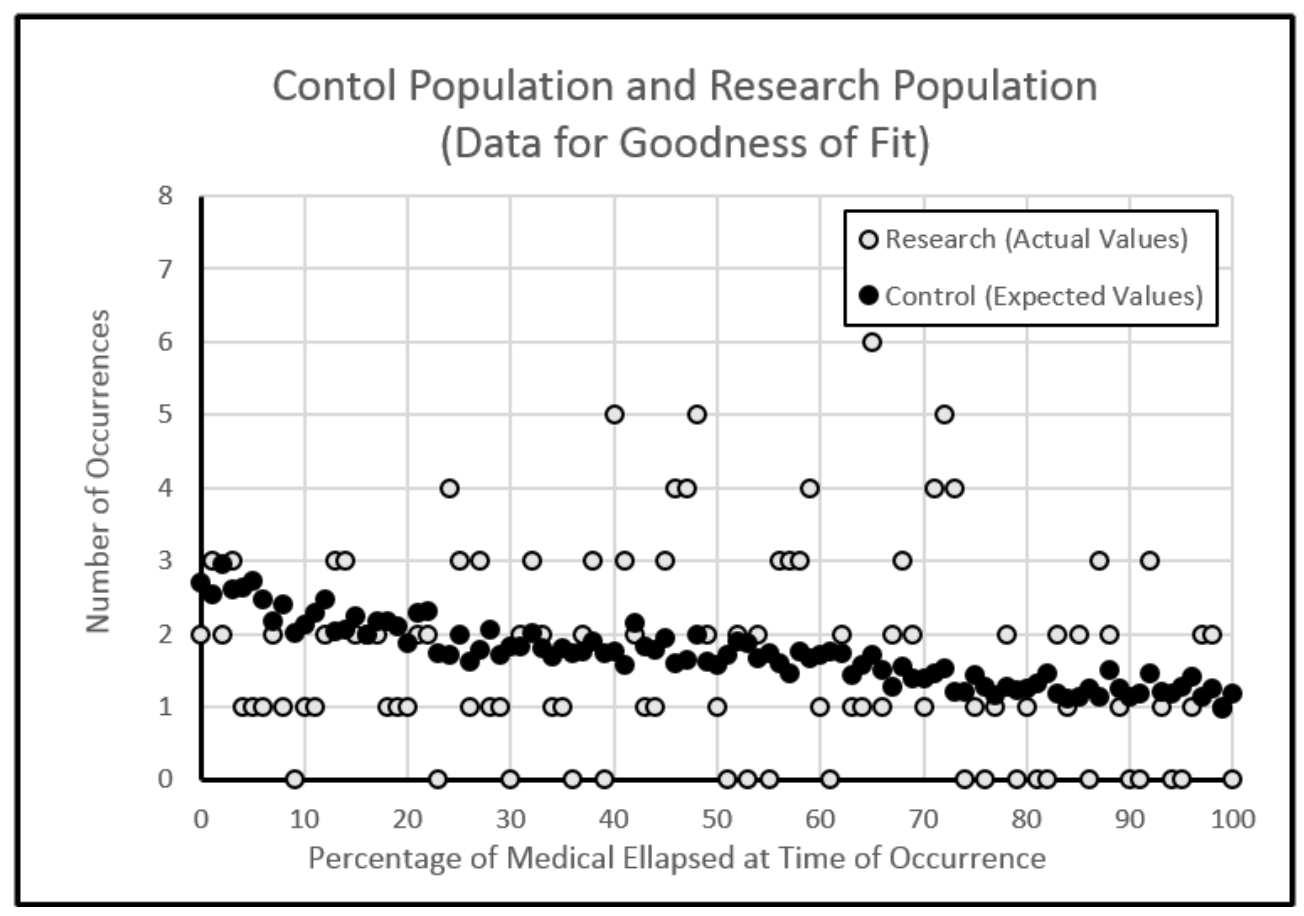

Figure 4. Control population and research population (Data for goodness of fit)

\section{Conclusion}

Most studies report a linkage if the probability that the null hypothesis is correct is found to be below $5 \%$. Some studies use a less rigorous standard of $10 \%$. The $17 \%$ probability found in this study does not meet 
either of these criteria. The statistics do not allow rejection of the null hypothesis, and so do not show a statistically significant linkage between percentage of medical elapsed and likelihood of incident occurrence. However, in the interest of safety, it is important to point out that the data does indicate an $83 \%$ likelihood that the two populations are statistically distinguishable in some form, however minute it may be.

While these findings are significant, they pale in significance compared to the unexpected negative correlation between percentage of elapsed medical time and likelihood of incident found in the control population. Statistically speaking, the more time that has elapsed since the third class medical, the less likely a pilot is to be involved in an incident or accident. This result is implied the existence of other unknown codependent variables, as it is not logical to assume that a medical evaluation in itself makes a pilot more dangerous. Logically, there are many possible explanations. The researcher and his colleagues have identified the following:

1. A private pilot who is not intending to fly is unlikely to renew his or her medical until that intention changes. Initial medical certification is certainly tied to an increase in flight activity as training commences. Recent medical recertification is probably tied to a similar increase in flight activity. Even if the per-hour likelihood of being involved in an incident is not increased, the increase in actual hours of flight activity would logically lead to an increased likelihood of incident.

2. Recent medical certification may be tied to complacency about emerging medical conditions that may lead to incapacitation or impairment.

3. Initial medical certification is tied to a lack of experience as a pilot. Recent medical certification is often tied to a lack of recent experience as a pilot. Decreased actual experience and decreased recent experience are both likely to increase the probability of involvement in incidents.

Regardless of the reasons for this statistical correlation, it is very strong. The coefficient of determination $\left(\mathrm{R}^{2}\right)$ was $82.1 \%$. This indicates that $82.1 \%$ of the observed variation in incident rate can be attributed to the linear regression model. Stated another way, $82.1 \%$ of a private pilot's historic risk of being involved in an accident or incident can be determined based solely on how recently he or she was issued his or her last third class medical. The likelihood that this variance could be attributed to random chance was calculated to be nearly zero $\left(\mathrm{p}<1 \times 10^{-160}\right)$, based on a $\mathrm{T}$ test against randomly generated data.

As previously noted, proponents of third class medical reform believe that the current medical certification process is burdensome and expensive. Opponents insist that the process is neither costly nor burdensome (Eidson, 2014; Webb, 2014). It is difficult to imagine why the amount of elapsed time since the issuance of a medical certificate is so strongly correlated to the likelihood of a pilot being involved in an accident or incident if the issuance of a third class medical is trivial to the pilot in question. 


\section{References}

Air Facts Journal (2013). The great debate: Should the $3^{\text {rd }}$ class medical be eliminated? Retrieved from http://airfactsjournal.com/2013/03/the-great-debate-should-the-3rd-class-medical-be-eliminated/

Aircraft Owners and Pilots Association \& Experimental Aviation Association (2012). Petition for exemption ... FAA-issued medical certificate. Available from from http://www.regulations.gov/

Eidson, M. (2014). Example letter to Congressman or Senator. Retrieved from http://www.supercub.org/forum/showthread.php?46526-Want-to-Know-What-the-AMEOrganization-Is-Saying-about-the-3rd-Class-Exemption

Federal Aviation Administration. (2008). FAR Final Rule. Retrieved from https://www.leftseat.com/nprm_faa_medical_certificate_duration.htm

Goyer, R. (2014). AMA Vote Reveals Dirty Secret of 3rd Class Medical. Fyying Magazine. Retrieved from http://www.flyingmag.com/blogs/going-direct/ama-vote-reveals-dirty-secret-3rd-class-medical

Pilot's Bill of Rights 2, S.571. 114th Cong. (2015) Retrieved from https://www.congress.gov

Spence, C. (2014). Third Class Medical Reform Caught in Government Maze. General Aviation News. Retrieved from http://generalaviationnews.com/2014/09/17/ third-class-medical-reform-caught-ingovernment-maze/

Webb, J. (2014). Third Class Medical Letter to FAA Administrator. Retrieved from http://www.asma.org/asma/media/asma/pdf-policy/2014/Third-Class-Medical-Letter-to-FAAAdministrator-4-9-2014.pdf 